\title{
UNA REFLEXIÓN
}

\author{
Ana Maria MACHADO \\ Escritora \\ anamaria.autora@gmail.com
}

\section{Resumen}

En un texto que, a la vez, es reflexivo en tono subjetivo, pero además busca ser objetivo según parámetros críticos, la autora lanza una mirada sobre su propia obra para niños y jóvenes, desde la publicación de sus primeros cuentos en 1969 y examina cómo se presenta en ella la cuestión de los géneros. Ubica su camino personal frente al desarrollo de la literatura infantil y juvenil de su país y busca relacionarlo con autores de su generación en el marco de sus circunstancias históricas y sociales. Analiza las características más constantes de sus textos y los eventuales cambios o aspectos distintos de su creación literaria personal, a lo largo de ese recorrido, tanto bajo su propia mirada autorreflexiva como según el análisis crítico de académicos que escribieron sobre su obra y abordaron ese aspecto. Además, comenta algunos retos específicos que encuentra en la labor cotidiana de escribir, frente a reglas gramaticales portadoras de marcas de género en los idiomas ibéricos y su búsqueda de soluciones en la práctica creadora.

Palabras clave: reflexión, crítica, trayectoria de Ana Maria Machado, géneros literarios, estudios de género, lenguaje.

\section{UNE RÉFLEXION}

\section{Résumé:}

Dans un texte à la fois réfléchi sur un ton subjectif, mais cherchant également à être objectif en 
Una reflexión

fonction de paramètres critiques, l'auteure jette un coup d'œil sur son propre travail pour les enfants et les jeunes, depuis la publication de ses premiers contes en 1969 et examine comment la question du genre y est présentée. Elle situe son parcours personnel devant le développement de la littérature pour enfants et pour la jeunesse dans son pays et cherche à le relier aux auteurs de sa génération dans le cadre de sa situation historique et sociale. Elle analyse les caractéristiques les plus constantes de ses textes et les changements possibles ou différents aspects de sa création littéraire personnelle, tout au long de ce voyage, à la fois sous son propre regard autoréflexif et selon l'analyse critique d'universitaires qui ont écrit sur son travail et abordé cet aspect. En outre, elle commente certains défis spécifiques qu'elle rencontre dans le travail quotidien d'écriture, face aux règles grammaticales portant la marque du genre dans les langues ibériques et à la recherche de solutions dans la pratique créative.

Mots-clés: réflexion, critique, trajectoire d'Ana Maria Machado, genres littéraires, études de genre, langage.

\section{A REFLECTION}

\section{Abstract}

In a text which is, at the same time, reflective in a subjective tone, but which also seeks to be objective according to critical parameters, the author casts a glance at her own work for children and young people, from the publication of her first stories in 1969 and she examines how the issue of gender is presented. She locates his personal path against the development of children's and youth literature in her country and seeks to relate it to authors of his generation within the framework of their historical and social circumstances. She analyzes the most constant characteristics of her texts and the possible changes or different aspects of her personal literary creation, along that route, both under her own self-reflexive gaze and according to the critical analysis of academics who wrote about her work and who addressed that aspect. In addition, she comments some specific challenges which she finds in the daily work of writing,with regards to grammatical rules bearing gender marks in the Iberian languages and her search for solutions in creative practice.

Keywords: reflection, criticism, Ana Maria Machado's career, literary genres, gender studies, language. 


\section{Ana Maria Machado}

Ustedes me invitan a echar una mirada sobre mi obra infantojuvenil y, con eso, a hacer una reflexión sobre cómo se muestra en ella la cuestión de los géneros. No es un reto fácil. Nunca es fácil para mí, como una autora acostumbrada a laborar en la zona del lenguage poético y creativo, cuando me piden algo así. O sea, que abandone esa región cálida de la creación, donde lo inconsciente y la memoria son señores, y pase a buscar la frialdad de un análisis objetivo. Incluso en un caso como el mío, en que admito y reconozco que tuve una formación académica rigurosa y desarrollé un aparato crítico para examinar textos. Pero en esa condición, siempre lo hice con una lupa. No con un espejo. Textos de otros, no míos.

Además, aunque lo haya hecho en diversas ocasiones para tratar de obra ajena, debo reconocer que hace décadas decidí abandonar la actitud de lectura analítica y cambiar ese sombrero por otro, el de una actitud y un lenguaje más propios de la subjetividad, la invención y las búsquedas estéticas que caracterizan la creación literaria.

De todas maneras, con esas limitaciones y mezclas entre prática y teoría, intento seguir la sugerencia recibida y tratar lo que me piden. Inicialmente, creo que debo hacer, para este público, breves presentaciones de algunas de las obras que voy a mencionar. Aunque casi todas estén entre mis más de 80 títulos traducidos al castellano, muchas veces suele ocurrir que su distribución sea una suerte de rehén o prisionera de las políticas de distintas editoriales, que buscan siempre elegir algunos títulos para hacerlos llegar a unos países pero no a otros, según criterios que jamás logré comprender. Entonces, parto del presupuesto de que son desconocidos aquí. Buscaré seguir un orden cronológico. Cuando cite esas obras, mencionaré siempre la editorial por la que está publicada en español la edición más reciente.

Empecemos por los inicios, como conviene. Aunque desde fines de 1969, yo ya escribía regularmente cuentos cortos para una revista infantil brasileña, Recreio, mi primer libro infantil no fue publicado hasta 1976, Bento-que-bento- é-o-frade / Al Don Pirulero (Planeta, Argentina). 
Una reflexión

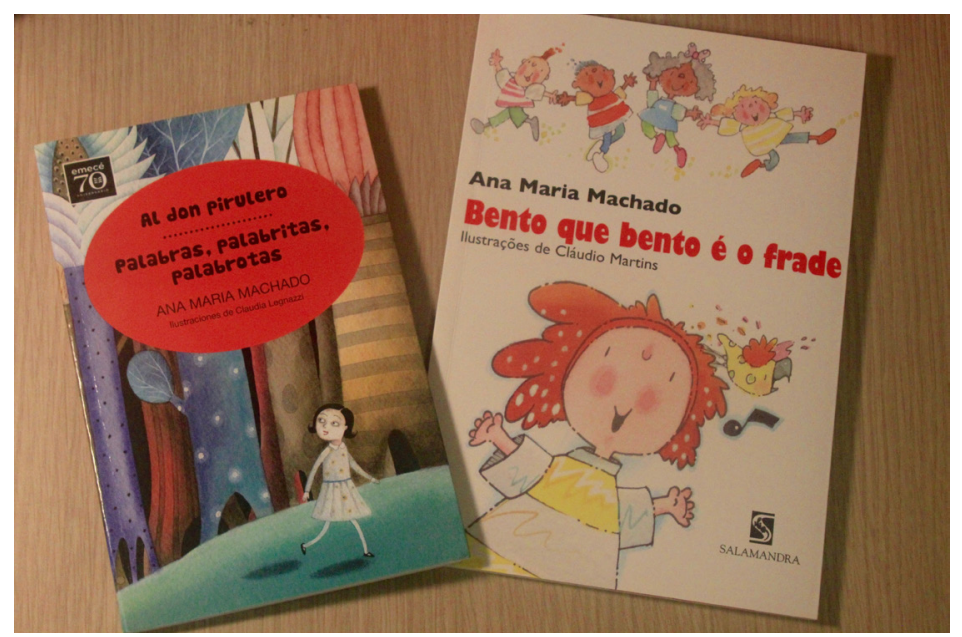

Fig. 1 Palabras, palabritas, palabrotas/Bento que bento é o frade

Hacía entonces 12 años que Brasil vivía bajo un gobierno militar. Una de las características de ese tiempo era la falta de respeto a la constitución, sustituyéndola por decretos y leyes ilegítimas, que se presentaban como una fachada jurídica, una manera de justificar que se encarcelaran opositores, se prohibiera la libertad de prensa, de cátedra y de reunión, se cerrara el Congreso cuando les daba la gana, se destituyeran jueces - enfín, todo el sistema que nuestros países conocen tan bien a partir de sus variadas y parecidas experiencias. En mi libro, entonces, yo partía de un juego infantil tradicional, al que jugaban un grupo de chicos y la protagonista es Nita, una niña rebelde, que no quiere obedecer y se niega a "hacer todo lo que el señor manda" como piden las reglas del juego. No le gusta recibir órdenes, rechaza la obediencia, y sale por el mundo en un viaje de búsqueda hacia un sitio donde todos puedan hacer lo que les dé la gana. En una serie de situaciones divertidas, más o menos realistas o imaginarias, esa rebelde vive ejemplos de anarquía total donde nada funciona, o bien se encuentra en situaciones de nuevas reglas, ahora reinventadas colectivamente. Hasta hoy me sorprende el rol que la lectura de esa historia terminó por tener en las discusiones sobre la nueva Constitución, finalmente votada y promulgada doce años después, en 1988. También me sorprende cómo el libro sigue de actualidad en nuestros días. Atribuyo mucho de eso a la fuerza vital de Nita, esa chica rebelde, desobediente, determinada a pensar con su propia cabeza - tan parecida a mí que incluso su nombre es una corruptela de Anita, diminutivo de Ana. Pero de eso yo no me daba cuenta cuando la creé, sólo lo descubrí más tarde, cuando lo señalaron la crítica y los maestros.

Dos años después, en 1978, gané un concurso de originales inéditos y así publiqué el libro que me 


\section{Ana Maria Machado}

dió mi primer premio importante y me abrió las puertas del mundo editorial, cuando varios editores empezaron a pedirme libros - y yo tenía cajones llenos de lo que escribía hacía casi diez años, sin saber adonde dirigirme para mostrarlo ni qué hacer con ello. Fue Historia Medio al Revés (Fondo de Cultura, México).

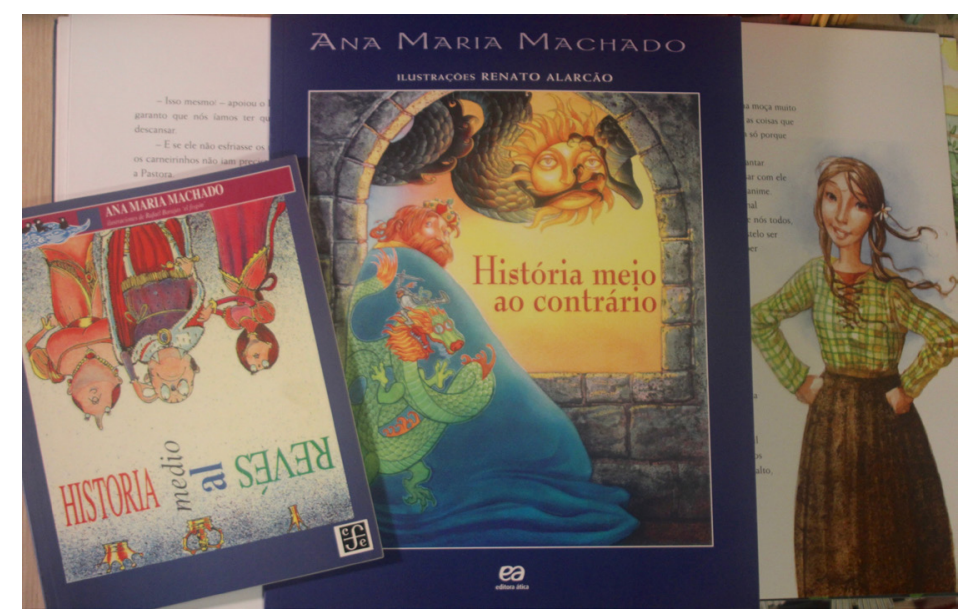

Fig. 2 Historia medio al revés

Cuando empecé a escribir ese relato, creía que iba a hacer una variante de un mito de origen, alrededor de la idea de cómo nació la noche. Ocurría en un reino, donde un dragón negro de un único ojo, que lanzaba humo por la boca, estaría robando al día, y con eso despertando la ira del rey. Siendo un reino, tenía reyes y la princesa, su hija, era algo rebelde, además de ver el ridículo del autoritarismo de su padre. Mientras la historia se desarrollaba, yo estaba segura de que ella sería una heroína, sobretodo cuando llega un príncipe casi ridículo con pretensiones de héroe. Pero entonces, yo misma me sorprendí: en su camino, el príncipe busca informarse con una pastora sobre las direcciones del sitio donde vive el dragón. Y ella percibe que su intención es matar al monstruo. Entonces ella decide no ayudarlo en su idea de acabar con aquella presunta amenaza, porque percibe que el pueblo echará de menos la luna (que era el ojo del monstruo), aquella neblina refrescante para las plantas del valle (que le salía como humo de la boca del dragón) y aquel tiempo de oscuridad que permitía algún reposo a los campesinos y trabajadores en general. Esa pastora se convierte en la nueva heroína, convence al príncipe de sus ideas, organiza el pueblo del reino para defender colectivamente al dragón y, al final, la única manera de que ese príncipe, ya totalmente enamorado de esa plebeya, pueda quedarse con ella no es convirtiéndola en princesa, sino convirtiéndose él en un hombre del pueblo, un vaquero. Y la 


\section{Una reflexión}

princesa? Decidió marcharse del reino e ir a estudiar en alguna república.

En 1980, publiqué Del tamaño justo (hoy editado por Norma/Educativa, de Bogotá), en que la protagonista Helena es una chica que busca descubrir quién es y cuánto vale y puede, ya que en su casa siempre le dicen que es demasiado pequeña para ciertas cosas o ya creció mucho y es demasiado grande como para pasarse la vida jugando.

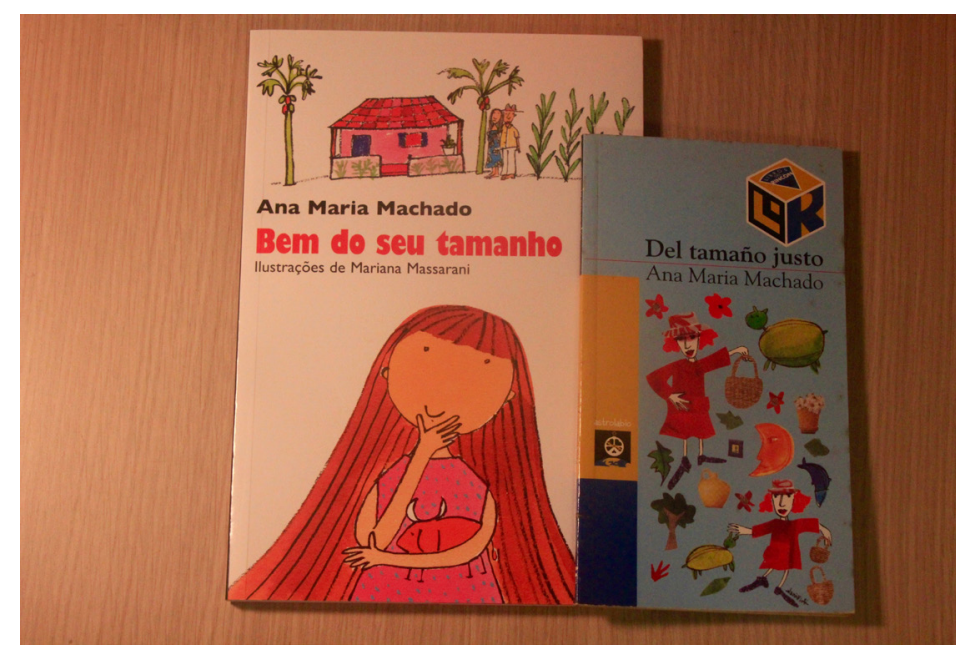

Fig. 3 Del tamaño justo

No voy a seguir mencionando todas las historias que escribí. Pero con esa evocación de mis primeras obras, quise destacar que, desde el inicio de mi carrera de escritora, tuve una neta predilección por personajes femeninos fuertes, autónomos, cuestionadores, rebeldes, de algunas formas transgresoras. Incluso en libros en los cuales el protagonista era un niño, como en el mismo año de 1980 Raúl Pintado de Azul (hoy también publicado por Norma/Educactiva, Bogotá), es una chica, Estela, la que le enseña los caminos para comprender su problema y llegar a solucionarlo, en dirección de la autonomía y de la decisión de enfrentar la dificultad por sus propios medios. 
Ana Maria Machado

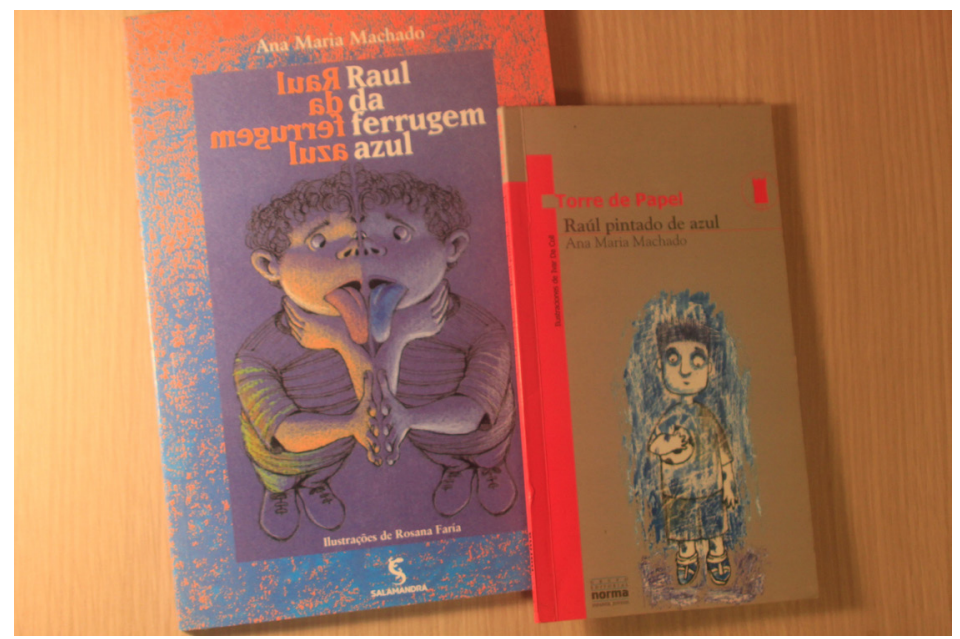

Fig. 4 Raúl pintado de azul

Y en 1981, con Palabras, Palabritas, Palabrotas, (Planeta, Buenos Aires) vuelve a destacarse una

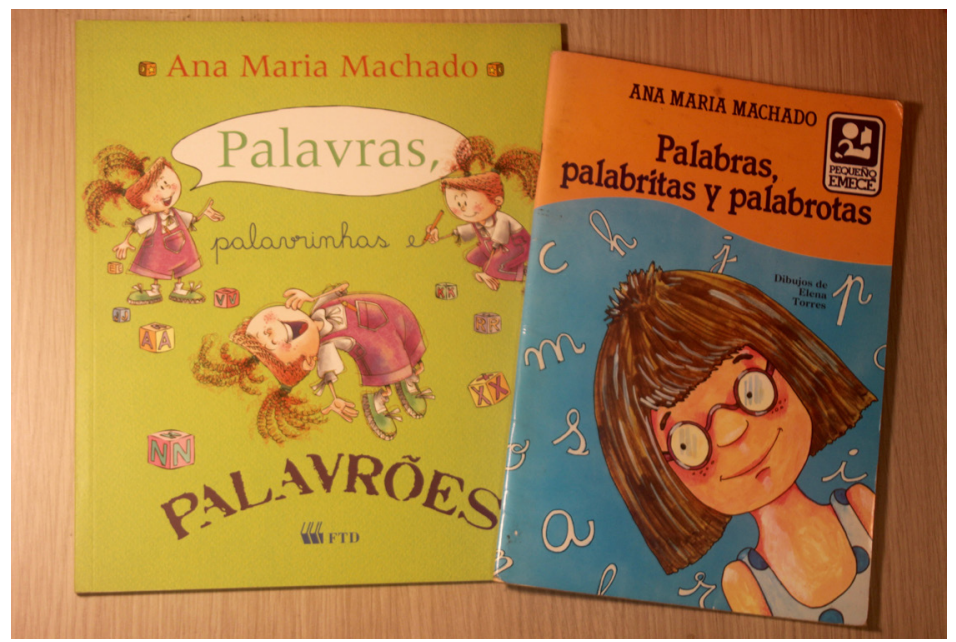

Fig. 5 Palabras, palabritas y palabrotas

niña que no se deja encuadrar en los modelos ejemplares de buena conducta y lleva su rebeldía al punto de confrontar el mismo lenguaje y las buenas maneras que la sociedad esperaba del sexo femenino.

Pero probablemente el mayor éxito que tuvo una de mis niñas fue a partir del año siguiente, 1982, con Bisa Bea, Bisa Bel (actualmente publicado por Fondo de Cultura, México), un libro que se convirtió en un clásico, ganó todos los premios en mi país, fue traducido en 12 idiomas, vendió 2 y medio millones de copias. 
Una reflexión

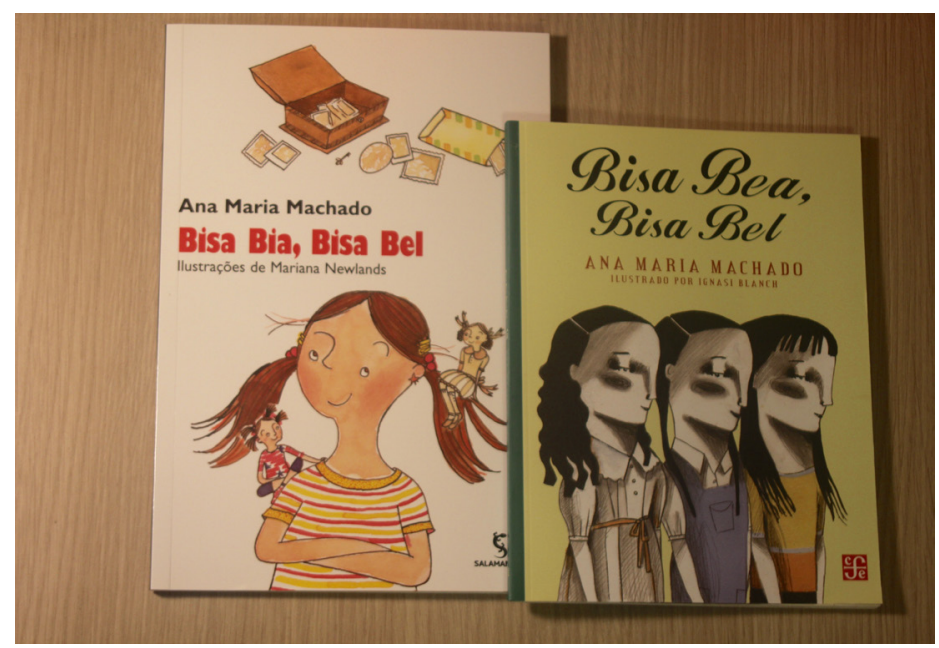

Fig. 6 Bisa Bea, Bisa Bel

Cuenta la historia de la niña Isabel, que un día se encanta con la foto de su bisabuela Beatriz cuando era una niña de su edad. Tanto pide e insiste, que su madre deja que se lleve la foto a la escuela para enseñarla a los amigos. Pero la niña pierde la foto e inventa que, como la guardaba por dentro de la ropa, junto a su corazón, mientras corría y sudaba la imagen se convirtió en un tatuaje transparente y ahora vive dentro de ella. Con eso, llega una suerte de magia: la bisabuela pasa realmente a habitarla y a hablarle, a contarle cómo era la vida en otros tiempos, darle consejos de cómo debe comportarse una chica. Por una parte, se hacen amigas, con una complicidad femenina. Por otra, hay choques y conflictos sobre el rol de las mujeres en la sociedad y los cambios que el tiempo trae respecto a eso. Y todo se complica todavía más cuando la futura bisnieta de Isabel también le habla desde dentro, venida del siglo siguiente y todavía es más transgresora, atrevida e impertinente que la misma Isabel.

Algunos trabajos académicos se ocuparon de la cuestión del género en ese libro. Transcribo una cita de uno de ellos, para traer otra voz hablando sobre el libro, la de Alice Gomes Xavier, de la Universidad de Goiás.

\footnotetext{
A nova mulher e a mãe que trabalha, assim como as novas estruturas familiares, podem ser observadas em boa parte das ficções de Ana Maria Machado e suas personagens demonstram nitidademente as modificações decorrentes da evolução social.

Em Bisa Bia, Bisa Bel, o tema é posto em questão, pelo confronto de várias gerações de mulheres da mesma família, num diálogo que se entrelaçam presente, passado e futuro. Na fantasia de Isabel, vozes de sua bisavó já morta e de sua bisneta que ainda não nasceu se confrontam e a menina se depara com a memória de sua família, construindo identidade e demonstrando as diferenças ideológicas marcadas por concepções sobre o papel feminino no decorrer do tempo. O confronto de pensamentos e valores nitidamente expostos na narrativa deixam claro a importância da imagem da memória na construção da identidade individual e no desenvolvimento de uma nova estrutura social. Isabel não só é representante
} 


\title{
Ana Maria Machado
}

dessa nova estrutura, como de uma outra possibilidade de vida, num futuro projetado em sua bisneta. ${ }^{1}$

Otra crítica importante, Regina Zilbermann, de la Universidade Federal do Rio Grande do Sul, incluye un análisis des estos personajes en su ensayo sobre voces femeninas en mi obra de ficción para adultos, tratando ambas vertientes una al lado de la otra. Transcribo parte de lo que ella escribe sobre esta obra infantil:

\begin{abstract}
Do diálogo entre a bisavó e a bisneta, nasce o cotejo entre dois tempos e duas visões da mulher, a antiga e convencional, representada por Bia, e a moderna e descontraída, encarnada por Bel.

Com o andar da intriga, introduz-se uma terceira perspectiva, a da Neta Beta, de quem Bel é bisavó. A voz do futuro é interpolada à narrativa, para dar conta das transformações que afetam as concepções da mulher. Assim, nenhum ponto de vista - seja o do passado, o do presente ou o do futuro - é definitivo, conclusão a que chega Bel, após a experiência tridimensional do tempo.

Assim sumariado, Bisa Bia Bisa Bel é o que se poderia chamar um livro feminista, não apenas porque traduz o processo de independência da mulher ao longo da história, marchando do convencionalismo e obediência de Bia à completa autonomia e autoconfiança de Beta. Mas também porque elege um ângulo feminino para traduzir essas questões, revelando como o processo de liberação nasce de dentro para fora, não por ensinamento, mas enquanto resultado das experiências vividas. É o que se passa com Bel, a menina que se transforma internamente, sem deixar de ser ela mesma, ou, em outras palavras, o que ela poderia ser, considerando as coordenadas de seu tempo.

Sob esse ângulo, Bisa Bia Bisa Bel traz para o interior da literatura infanto-juvenil um debate que alimentava não apenas a ficção brasileira no período, mas também os estudos literários, dado o crescimento da chamada Crítica Feminista, em vias de se metamorfosear em Crítica de Gênero. Contudo, a obra incide igualmente em um renovado processo de criação, assinalado pela interlocução entre as personagens de temporalidades diferentes, de que decorre o dialogismo que embasa o desenrolar do enredo.

Com efeito, o enredo depende substancialmente de as personagens terem condições de conversar entre si, apesar da distância temporal. Ou, colocado em outros termos, de Bel, a protagonista, aceitar a interpolação da voz do passado em seu próprio discurso, assim como não se negar a ouvir as manifestações do futuro, emanadas de neta Beta. ${ }^{2}$
\end{abstract}

Como llevo cerca de medio siglo escribiendo para niños y jóvenes, tengo una obra vasta. No voy ahora a hacer el comentario de todos mis personajes femeninos en todos mis libros. Pero puedo decirles que son muchas niñas, jóvenes y mujeres, todas cuestionadoras e imaginativas, dispuestas a enfrentarse a imposiciones de roles tradicionales o a buscar nuevas respuestas para viejas preguntas. No importa si se trata de una historia corta, destinada a los más pequeños (como Niña Bonita de 1996,editada por Ekaré en Caracas o como Abuelita aventurera también de 1986, publicada por SM en España o como Besos mágicos de 1996, publicado por CIDCLI en México),

1 Xavier, Alice Gomes - A Memoria em Bisa Bia, Bisa Bel, de Ana Maria Machado -dissertação orientada por Maria Zaira Turchi, Unversidade Federal de Goiás). http://www.sbpcnet.org.br/livro/63ra/conpeex/mestrado/trabalhos-mestrado/ mestrado-alice-gomes.pdf. Última consulta: 4-7-2019

2 Zilbermann, Regina (2017). Três tempos e várias vozes. ANA MARIA MACHADO-A AUDACIA DE UMA ESCRITORA. https://www.researchgate.net/publication/321960521_ANA_MARIA_MACHADO_-_A_AUDACIA_DE_UMA_ ESCRITORA. Última consulta: 16-7-2019. 


\section{Una reflexión}

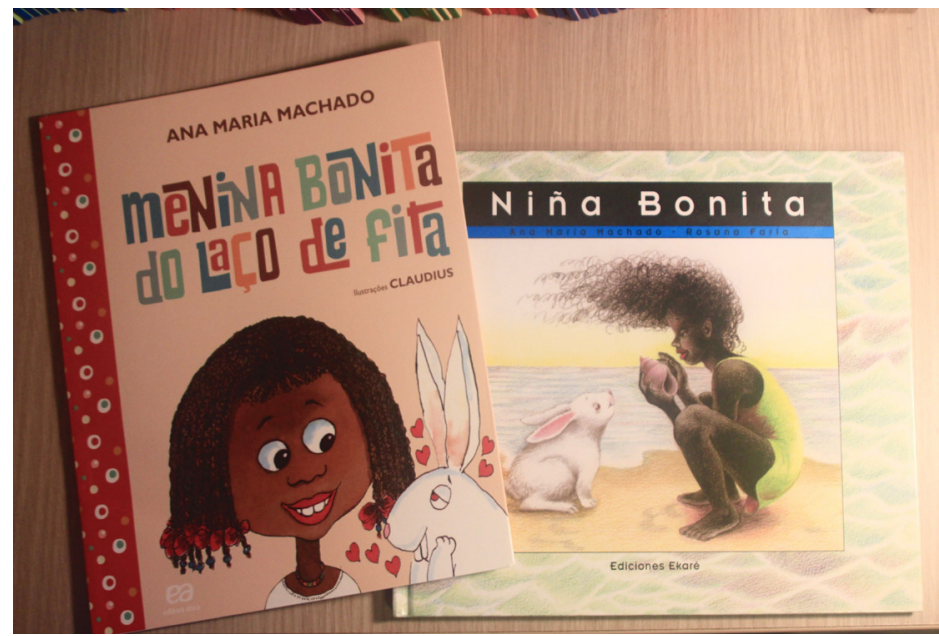

Fig. 7 Niña Bonita

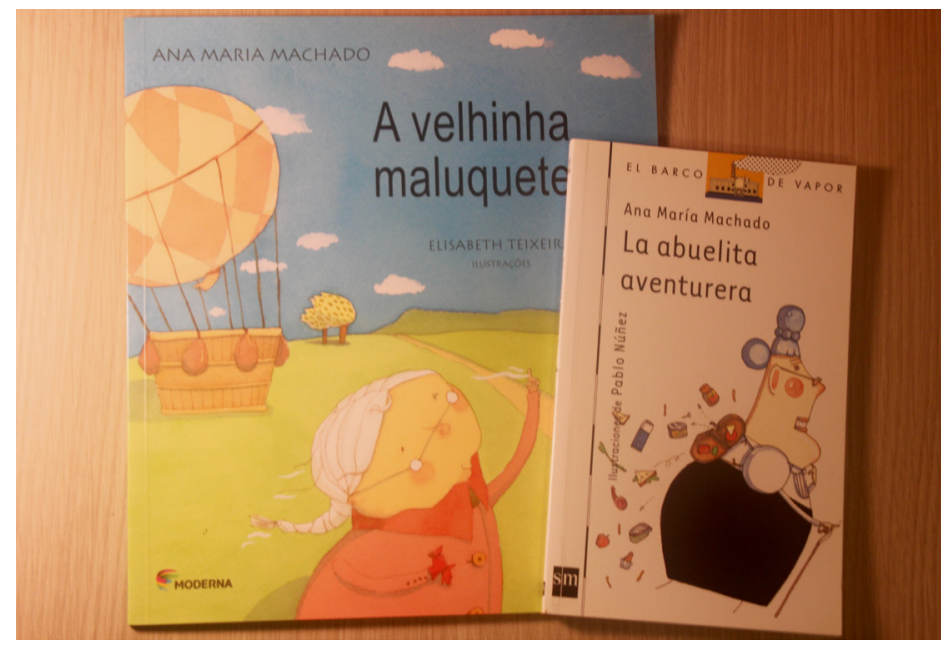

Fig. 8 Abuelita aventurera

o si es una novela para adolescentes, discutiendo cuestiones éticas, comportamentales, existenciales - como en Siempre con mis amigos, de 1999 (SM, España) o El canto de la plaza de 1986, Un deseo loco, de 1990, Misterios del mar océano, de 1992 o Eso no me lo quita nadie de 1994, todos ellos publicados en español por Norma-Educativa, de Colombia). 
Ana Maria Machado

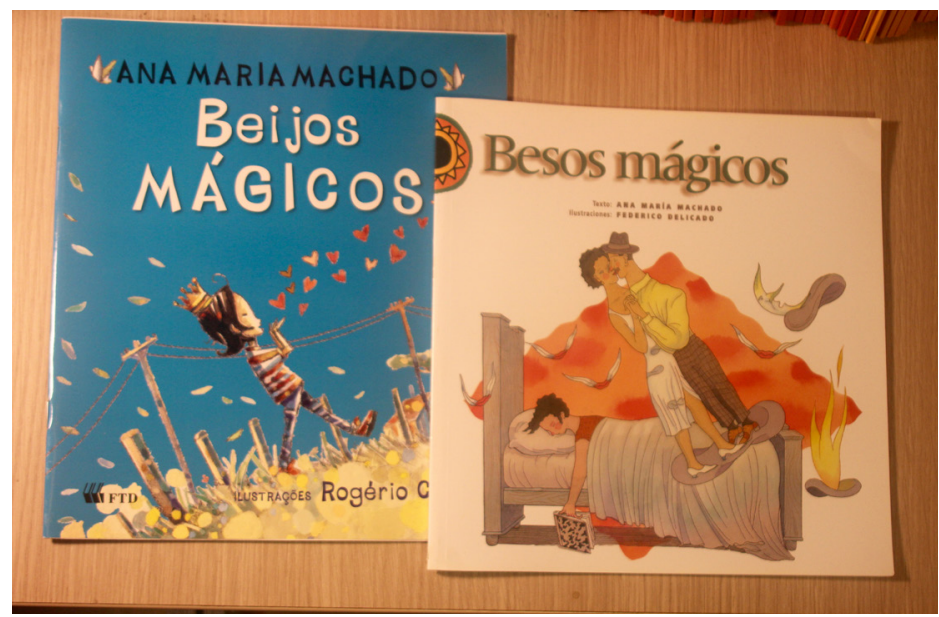

Fig. 9 Besos Mágicos

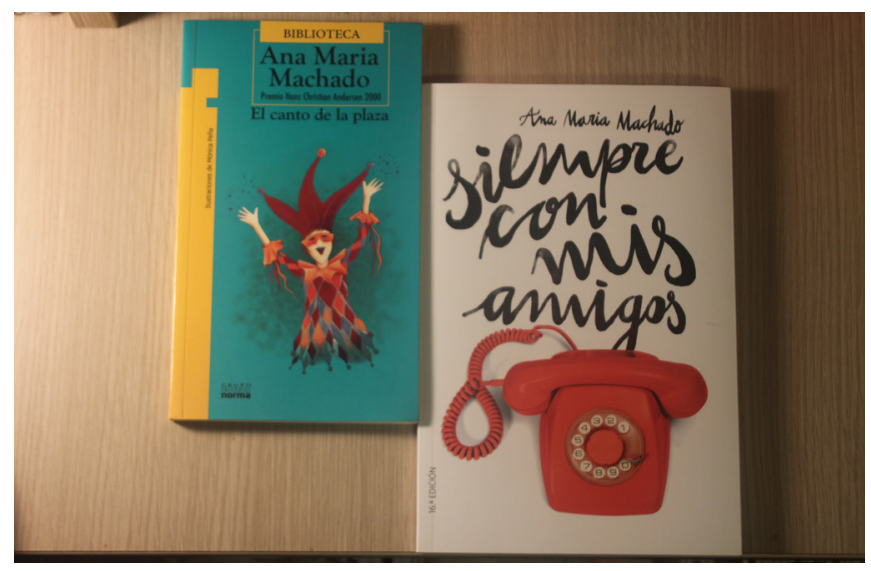

Fig. 10 Siempre con mis amigos

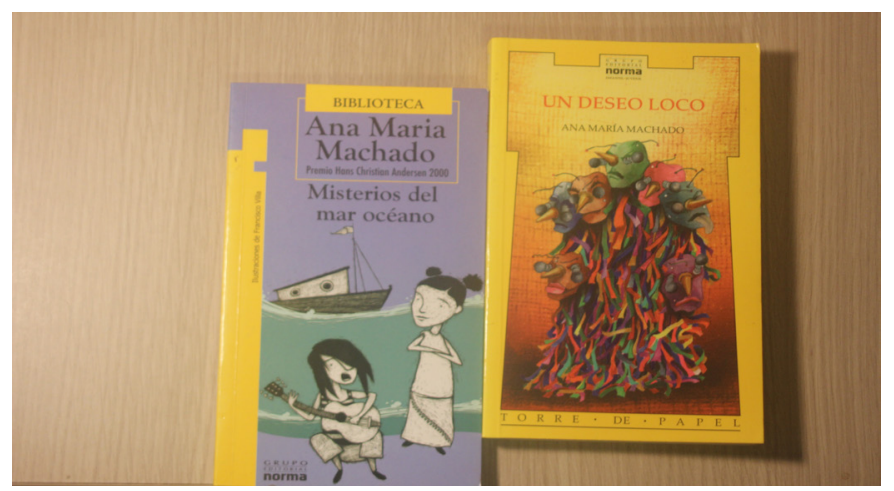

Fig. 10A Misterios del mar océano 
Una reflexión

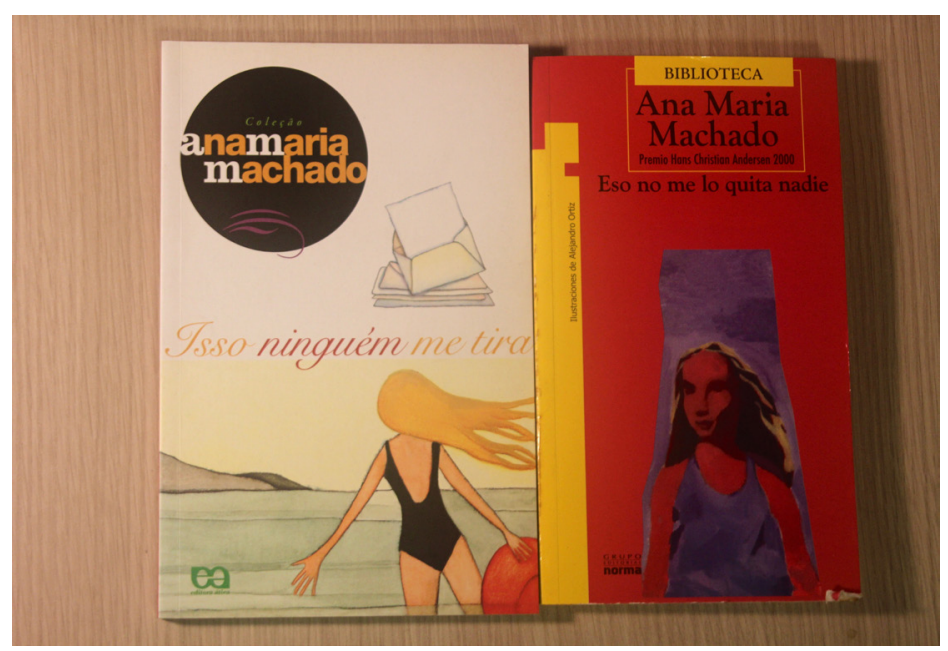

Fig. 11 Eso no me lo quita nadie

En el caso de este último, ocurre algo divertido porque frecuentemente da origen a calurosas polémicas entre los jóvenes en las escuelas. Empieza como una historia de un amor adolescente prohibido y que debe ocultarse, narrado desde distintos puntos de vista por distintas voces - la de Dora, una niña enamorada de un colega desde lejos, la de ese chico, Bruno, interesado en la prima de ella, la de su prima Gabi, encantada por Bruno, pero leal a Dora. Mientras el enredo se desarrolla y se plantean las cuestiones de ética y lealtad, las familias se mezclan en la situación, ocurren las prohibiciones, surgen nuevos marcos y las cosas van cambiando. El niño va a estudiar a otra ciudad y cuando vuelve, un año más tarde, todo está más tranquilo. Lo que parecía una historia de amor prohibido, como Romeo y Julieta, cambia poco a poco. Dora ya está interesada en otro chico, y los padres de Gabi ya aceptan su relación con Bruno. Todo parece marchar para un "final feliz". Pero entonces le toca a Bruno, quiere limitar la libertad de Gabi poco a poco, con sus celos y su deseo de controlar sus amistades, con quién baila, con quién sale, cómo viste. Y ella debe decidir qué será lo que no admite que nadie le quite, si su idea adolescente de amor romántico o su independencia cada vez más madura.

También en lo que escribí este siglo, están las niñas cuestionadoras y rebeldes - como en $\mathrm{Del}$ otro mundo (de 2002) y Mensaje para ti, de 2007 (ambos en castellano publicados por la editorial colombiana Norma/Educactiva). 
Ana Maria Machado

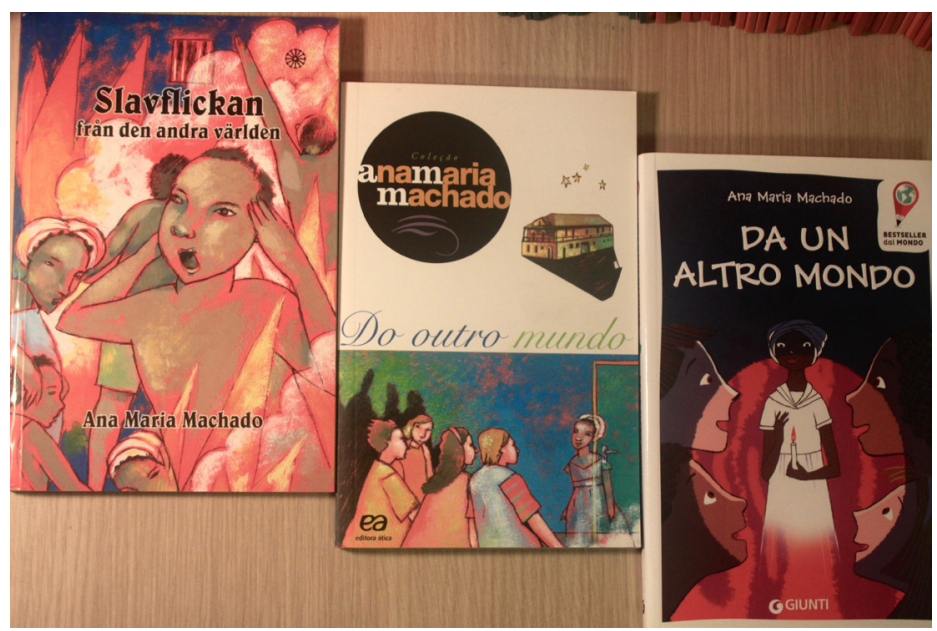

Fig. 12 Del otro mundo

El primero tiene una fantasma femenina, adolescente y negra, que había sido esclava y surge frente a los personajes para pedirles una acción como forma de justicia. Para eso, les cuenta lo que pasó a los esclavos que vivían en aquel sitio durante la esclavitud, en el siglo XIX y las historias del pasado y del presente se mezclan.

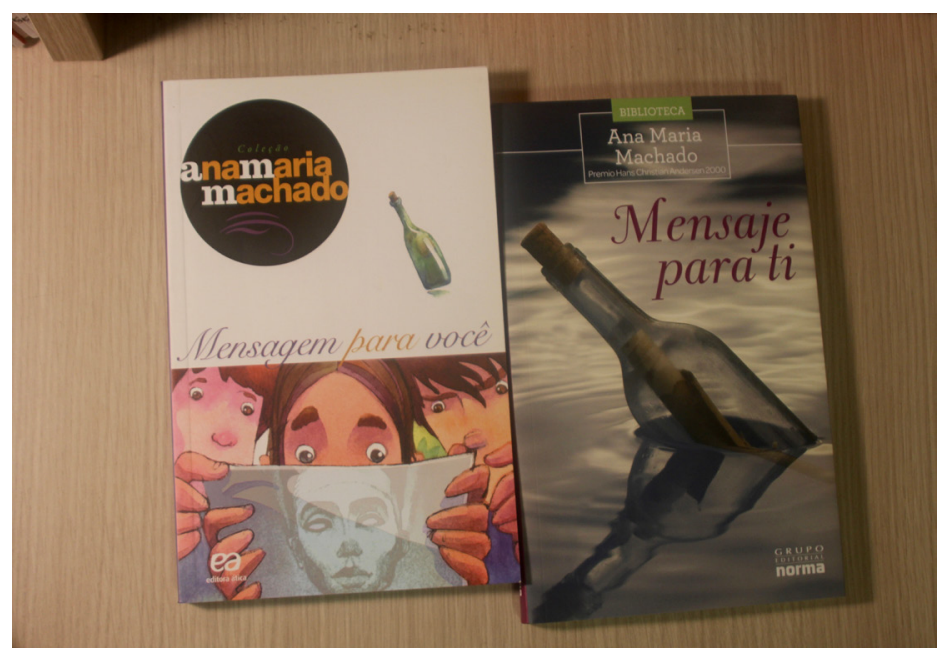

Fig. 13 Mensaje para ti

De otra parte Mensaje para tí hace un recorrido histórico, cuando un grupo de adolescentes recibe mensajes de orígenes misteriosos en sus teléfonos, computadoras, juegos eletrónicos, y poco a poco se dan cuenta de que vienen de épocas distintas, a veces de personas que realmente existieron, a veces de desconocidos. Lo que tienen en común es que sus autores tenían la capacidad de escribir y valorar la escritura, pero eso lleva también a discutir las diferencias de educación entre hombres y mujeres en la historia y las oportunidades, interdicciones y los roles profesionales de los géneros en distintos siglos 


\section{Una reflexión}

y lugares.

Finalmente, comento uno de mis títulos juveniles más recientes, Hasta que llegue el día, de 2013,

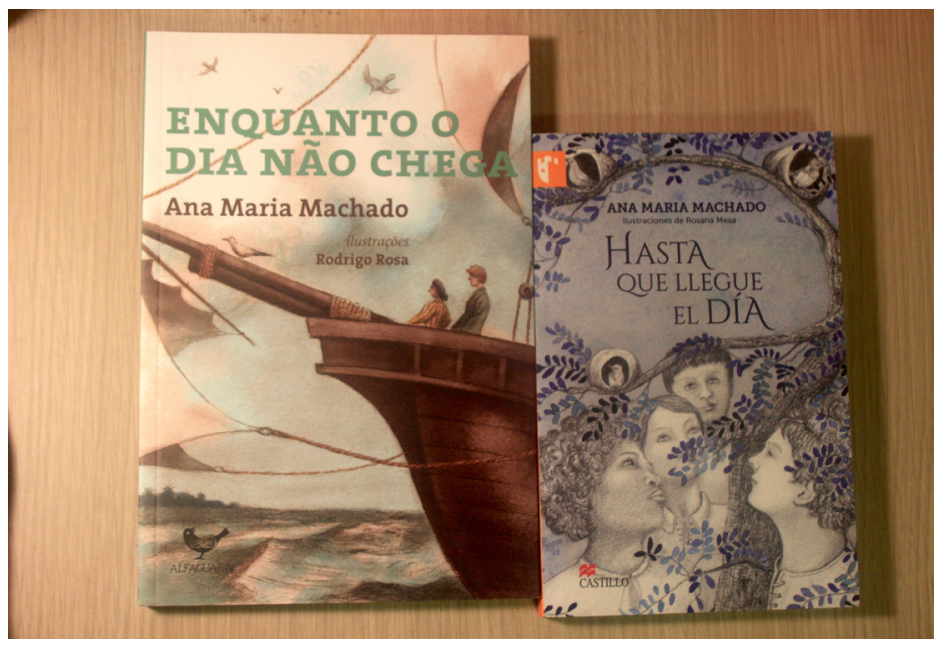

Fig. 14 Hasta que llegue el día

publicada en español por la editorial mexicana Castillo/ MacMillan. Quiero hablar de ese título porque en él desarrollé una idea muy difícil que yo quería enfrentar hacía años - tener como protagonista a alguien que el lector no sabe si es hombre o mujer. No porque sea andrógino, sino porque el narrador no declara su género y el idioma no lo revela hasta la mitad del relato. Entonces, creé esa o ese personaje que se llama Manu (puede ser Manuel o Manuela) y vive en el campo con Bento, su hermano mayor, en Portugal del siglo XVI, cuando la peste mata a sus padres y ellos huyen para Lisboa. Allá, trás una pelea en una taberna, Bento es hecho prisionero y termina por ser deportado a Brasil. Para no apartarse de él, Manu logra embarcarse casi clandestinamente en la misma carabela. El libro continúa con lo que viven en tierras brasileñas y la amistad que establecen con un chico indígena que allá conocen y con un adolescente africano, cuya vida habíamos seguido desde que lo hicieron prisionero en África y lo llevaron a Brasil como esclavo . Y Manu decide organizar su liberación y ayudarlo a huir a un pueblo de esclavos evadidos en la floresta, convenciendo a los otros para que participen en su plan. Pero hasta el momento en que es necesario revelar eso, el lector no sabe si Manu es Manuel o Manuela, esa cuestión no se plantea; todos (incluso los lectores) creen siempre que es un chico, porque es valiente y toma iniciativas. Se trató de un juego con el punto de vista del protagonista y con los prejuicios que traemos a la lectura. Escribir eso de esa manera fue una dificultad inmensa. Jamás podía decir yo que Manu estaba contento o contenta. Tenía que emplear una palabra como feliz, por ejemplo. Algún 


\section{Ana Maria Machado}

adjetivo que no terminara en -a- $\mathrm{u}$-o-, para no revelar el género. Tampoco yo podía llamar la atención de la ambiguedad del texto, porque mi objetivo era que el lector o la lectora imaginara a Manu como quisiera $y$, solamente cuando es importante para la narrativa, se revela que es una niña vestida de niño y con el pelo corto porque su hermano Bento decidirá disfrazarla así, porque quiso protegerla durante el viaje desde su pueblo. Yo quería que el lector o lectora trajera sus preconcepciones a la lectura, sin dar cuenta si yo estaba hablando de niño o niña. Para eso, además, tuve el cuidado de, en portugués, emplear palabras que pudieran referirse a los dos casos, como "criança", "vulto", "sombra". Para mí, como escritora, esa fue una experiencia muy rica: trabajar esa dificultad con naturalidad, dentro de ese marco de género gramatical que tenemos en nuestras lenguas, el portugués y el castellano.

Pero eso planteó problemas terribles para las traducciones. Desafortunadamente, la traducción en castellano no logró mantener ese juego de la misma manera rigurosa. Por ejemplo, me gustaría que el sobrenombre del personaje (Miudim o Menudim, en portugués un nombre común de dos géneros) fuera algo un poco neutro, como Chiquín o Flaquín, pero la opción fue por Flaquito... Y eso ya funciona de otro modo, pues engaña al lector, haciéndole creer en un género para después revelar otro.

También para la traduccion en inglés resultó imposible mantener esa ambiguedad porque para ellos hay que hacer la concordancia de los pronombres posesivos según el género de aquél que posee (his table or her table mientras decimos su mesa siempre, no importando si el mueble tiene un dueño o una dueña). Además, en inglés casi nunca se puede usar el sujeto oculto, porque la conjugación de los verbos repite la misma forma para distintas personas y el pronombre personal es la manera de hacer la distinción. Entonces, para algo sencillo que podemos decir en nuestras lenguas como "Manu llegó tarde. Como tenía hambre, comió todo el pan", sin sujeto evidente, ellos tienen que decir "Manu was late. As he (o she) was hungry, he (o she) ate all the bread."

En la práctica, esa experiencia fue para mí una revelación de algunos mecanismos íntimos de nuestros idiomas, un aspecto que me hizo comprender incluso algunas exigencias hechas por movimientos feministas de lengua inglesa que a veces pueden parecernos exageradas, defendiendo ciertos cambios lingüísticos. Es que, en ciertos aspectos, la gramática de su idioma parece ser más autoritaria que la de los nuestros, si se puede decir así.

De la misma manera que en mis 10 obras de ficción para adultos (de las cuales dos novelas están publicadas en España por Alfaguara, Sol tropical de la libertad y Palabra de honor), en general, la 


\section{Una reflexión}

crítica señala el rol de ruptura de estereotipos de género y de desconstrucción del poder patriarcal que

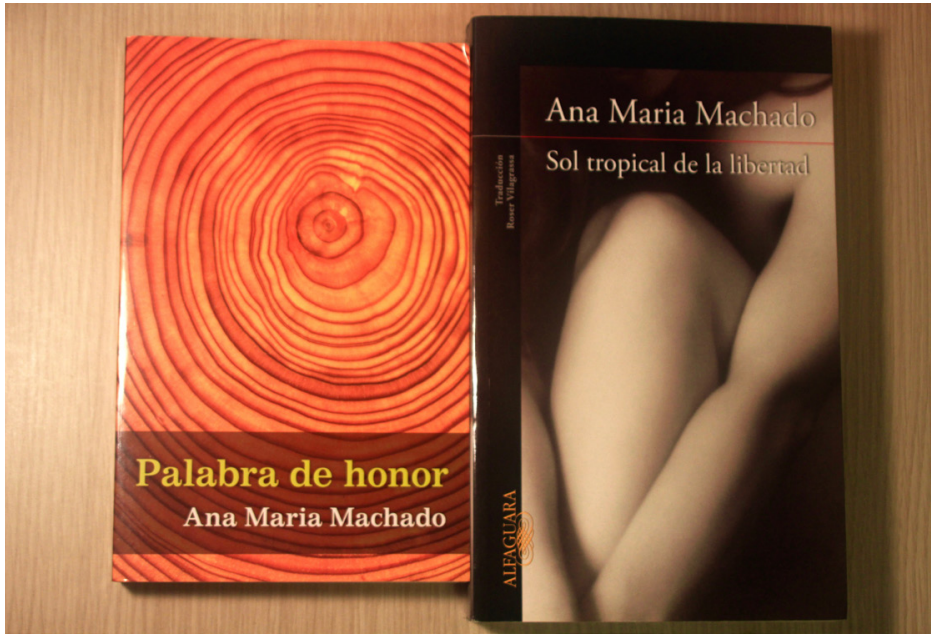

Fig. 15 Palabra de honor y Sol tropical de la libertad

tienen mis personajes femeninos ${ }^{3}$. O subraya la reinvención de distintas mujeres en distintas fases cronológicas (niñas, adolescentes, madres, abuelas) que revolucionarán los estereotipos tradicionales, creando nuevos iconos femeninos, rechazando modelos basados en la dominación o en los prejuicios ${ }^{4}$.

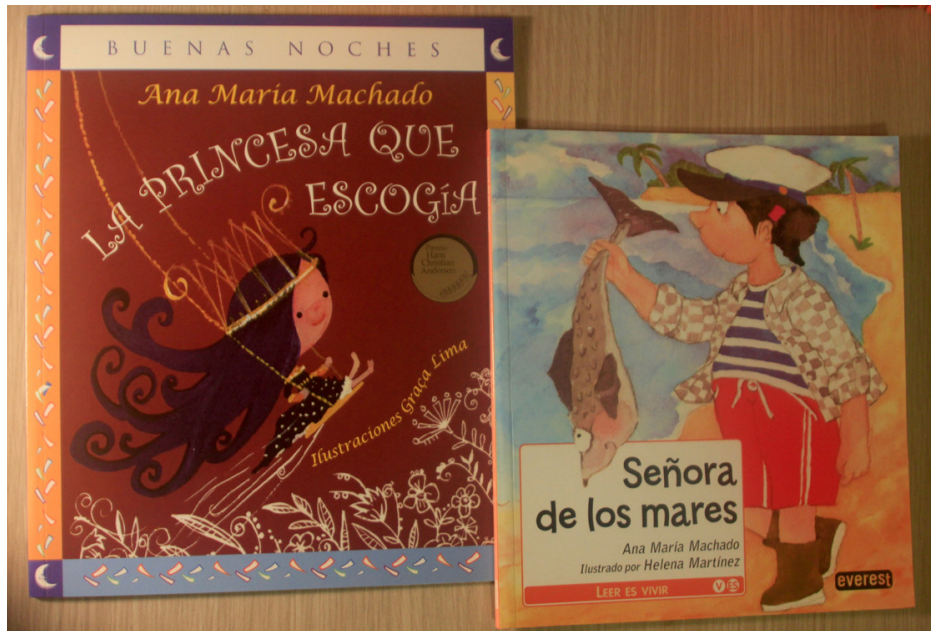

Fig. 16 Señora de los mares

Es el caso, por ejemplo, de un libro como Señora de los mares, un relato construido a partir de recursos familiares de mi niñez, cuando los pescadores del pueblo donde mis abuelos tenían casa y yo pasaba las vacaciones no aceptaban llevar mujeres al mar en sus embarcaciones, por miedo a la mala

3 Farias, Leila Wanderleea Bonetti (2007). A Audácia dessa mulher: Ana Maria Machado e a Subversão do cânone na reescrita de Capitu, tese de mestrado orientada por Lúcia Osana Zolin, Universidade Estadual de Maringá, Paraná. http:// www.ple.uem.br/defesas/pdf/lwbfarias.pdf. Consulta: 24-6-2019.

4 Ribeiro, Francisco Aurelio (2002). Imagens do feminino em Ana Maria Machado e Lygia Bojunga Nunes. Signum. Revista do Curso de Letras do CESV, Vitória, ano III n. 3, jan. /jun. 


\section{Ana Maria Machado}

suerte. Y también de otro libro, La Princesa que escogía, donde construí una historia alrededor de una idea en la que siempre insistí con mis hijos - sobretodo con mi hija: tú siempre puedes decir NO.

De alguna manera, me reconozco en esas historias y en las observaciones de la crítica sobre lo que escribí. Y doy gracias a la vida, que me dio la oportunidad de dar una presencia activa a tantas mujeres en mis escritos, llevando sus voces a tantas partes distintas. Así, las traigo hoy a Zaragoza, tan lejos de mi abuela, mi madre, mis tías, hermanas, amigas, tantas mujeres que me formaron y tantas más de mi país y de otros, reflejadas en personajes míos como la voz con la cual termino estas palabras y que evoco en las páginas iniciales de Punto a Punto (Babel, Bogotá, 2007),

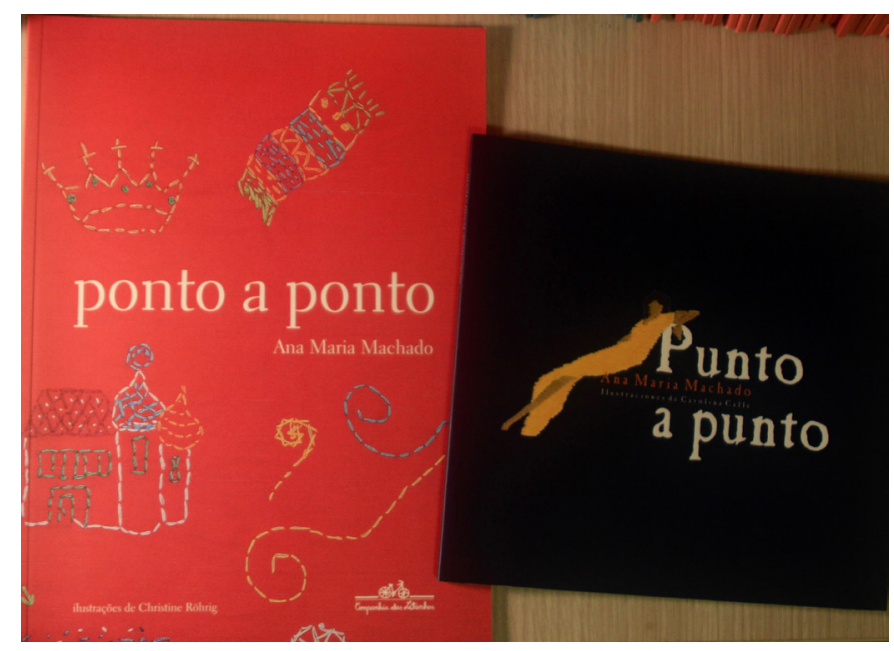

Fig. 17 Punto a Punto

Había una vez una voz. Delgado hilo sin rumbo. Hilacha de voz.

Voz de mujer. Dulce y mansa.

De rezar, arrullar niños, muchas historias contar.

De palabras de cariño y frases de consolar.

En toda y cada labor, voz de siempre concordar.

Voz débil y chiquitina. Voz de quien vive en sordina.

Pero cuando pasa el tiempo y crece la consciencia de todo lo fuerte que esa mujer mansa puede ser y de todo el poder que guarda en sí misma, toda la situación puede cambiar y esa presencia femenina se convierte en dueña de su propia voz, capaz de llegar muy lejos y cambiar su vida y la de otros. Como suele ocurrir y deseo que nos pase a todas. Aunque hayamos tenido que hacerlo a lo largo de los siglos y esa construcción de poder sea una labor paciente y constante, de todos los días y colectiva.

(Universidad de Zaragoza / Université de Bordeaux, Coloquio Internacional de Literatura Infantil e Juvenil, Zaragoza, 17, 18 y 19, de octubre de 2018). 